\title{
LAS NORMAS APLICABLES EN ESPAÑA ANTE EL COVID-19: UN ESTUDIO JURÍDICO APLICABLE ANTE LA CIUDADANIA ESPAÑOLA Y, LOS EXTRANJEROS RESIDENTES EN EL TERRITORIO NACIONAL
}

\author{
THE APPLICABLE RULES IN SPAIN FACE TO COVID-19: A LEGAL STUDY \\ APPLICABLE TO SPANISH CITIZENSHIP AND, FOREIGN RESIDENTS IN THE \\ NATIONAL TERRITORY
}

\begin{abstract}
Salvador Morales Ferrer
Doctor Honoris Causa por el Claustro Nacional de Doctores de México (Unam). Doctor en Derecho por el programa de Estudios Jurídicos, Ciencia Política y Criminología por la Universidad de Valencia. Miembro Del Ilustre Colegio De Abogados De Alzira.

E-MAIL: salvadormorales@icaalzira.com LATTES: http:/ /lattes.cnpq.br/63253297344936; ORCID: httos:/ / orcid.org/0000-0001-9084-3068
\end{abstract}

\begin{abstract}
RESUMEN: Desde los inicios de la humanidad el hombre siempre sufrió una serie de enfermedades, en este Siglo XXI en que vivimos por causas naturales la humanidad esta siendo castigada por la pandemia del coronavirus o, llamado Covid-19, a todo esto España es uno de los países más afectados en Europa después de Italia por eso, el Gobierno Español ha intentado frenarlo mediante medidas legislativas entre estas normas el Real Decreto 463/2020 de 14 de marzo, por el que se declara el estado de alarma para la gestión de la situación de crisis sanitaria ocasionada por el Covid-19, creando así el estado de alarma como medida de protección para los ciudadanos y ciudadanas españolas, como medida para que esta pandemia no se expanda en el territorio nacional, mediante la limitación de ciertos Derechos Fundamentales de la Constitución Española.
\end{abstract}

PALABRAS CLAVES: pandemia; Comunidades Autónomas; Limitación de Derechos Fundamentales; crisis sanitaria; Garantías gubernamentales

\begin{abstract}
Since the beginning of humanity, man has always suffered a series of diseases, in this 21st century in which we live for natural causes, humanity is being punished by the coronavirus pandemic or, called Covid-19, Spain is one of the countries most affected in Europe after Italy for that reason, the Spanish Government has tried to stop it by means of legislative measures among these rules Royal Decree 463/2020 of March 14, which declares the state of alarm for the management of the situation of health crisis caused by Covid-19, thus creating the state of alarm as a protection measure for Spanish citizens, as a measure so that this pandemic does not spread in the national territory, by limiting certain Fundamental Rights of the Constitution Spanish.
\end{abstract}


Keywords: Spanish Legislation against Covid-19, Suspension of the Autonomous Communities, Limitation of Fundamental Rights, Government Guarantees

KEY WORDS: pandemic; Autonomous communities; Limitation of Fundamental Rights; health crisis; Government guarantees

SUMÁRIO: 1 Introducción 2 El estado de alarma en España 3 El ámbito de la aplicación en materia de sanidad del Real Decreto 463/2020 4 Las funciones del ministro de sanidad $5 \mathrm{El}$ ámbito de aplicación en materia de interior ante los extranjeros irregulares respecto al Real Decreto ley 463/2020 5.1 El ámbito de aplicación en materia de interior ante españoles y extranjeros legales respecto al real decreto ley 463/2020 6 ¿Como actuará el ministro del interior ante el covd-10? 6.1 ¿Qué tipo de sanciones aplicará a los ciudadanos que incumplan las fuerzas de seguridad y cuerpos del estado? 6.2 La protección del ministro del interior ante los reos en las carceles por el covid-19 7 Las limitaciones de los ciudadanos españoles ante el Real Decreto 463/2020 de 14 de marzo, por el que se declara el estado de alarma en España 8 Las funciones de la Ministra de Defensa y el Ministro de Transportes en el Real Decreto 463/2020 de 14 de marzo, por el que se declara el estado de alarma en España 8.1 Los transportes por carrereta en españa durante la cuarentena por el covid-19 9 Transito aduanero en el estado de alarma por el Covid-19 en España 10 La suspensión de los estudios durante el estado de alarma en España 11 Conclusiones 12 Notas de referencia.

\section{Introducción}

Ante la gran proliferación de contagios de ciudadanos y ciudadanas españolas de la pandemia del coronavirus o, llamado Covid- 19, el Gobierno Español ha dictado una norma para el confinamiento en casa de los ciudadanos nacionales y, extranjeros esta norma se basa, mediante la Constitución Española de 1978 así lo menciona el artículo $116.2^{1}$ al señalar: El estado de alarma será declarado por el Gobierno mediante decreto acordado por el un plazo máximo de quince días, dado cuenta al Congreso de los Diputados, reunido inmediatamente al efecto y sin cuya autorización no podrá prorrogarse dicho plazo". Por lo que, la normativa que sea publicado en España, no podrá extenderse más de quince días, en el caso que se extendiera se tendrá que dar cuenta al Congreso de Diputados, al hilo cabe mencionar la Sentencia del Tribunal Constitucional ${ }^{2}$ que señala en sus Antecedentes de hecho g dispone: " con la autorización de la prórroga del estado de alarma en los mismo términos en los que fue inicialmente declarado, el Congreso de los Diputados había asumido en su integridad", por lo cual el Presidente del Gobierno Español, mediante el Congreso de Diputados podrá prorrogar el estado de alama por el Covid-19 en España. Con el presente artículo se pretende realizar un análisis descriptivo en los efectos jurídicos- normativos que hacen hincapié, ante el estado de alarma producido por Covid-19 en España. El artículo tiene la siguiente estructura: el primero esboza el significado de estado de alarma en España; el segundo presenta el ámbito de aplicación en el ministerio de sanidad por el Real Decreto 463/2020; el tercero aclara las funciones a las que se le atribuye al Ministro de Sanidad en la crisis del Covid-19 en España; el cuarto atiende a los efectos jurídicos de los inmigrantes irregulares en la crisis del Covid-19 en España; el quinto se analiza las situaciones de los españoles y los extranjeros legales en España ante esta pandemia; sexto se muestra como actuará el Ministro del Interior Español ante esta situación de situación de alarma; séptimo se esboza las limitaciones de los ciudadanos españoles ante el Covid-19; el octavo aclara las funciones del Ministra de Defensa y el Ministro de Transportes ante esta situación de alarma; el noveno aclara el transito 
aduanero entre España y los demás países; el décimo aclara la suspensión de las actividades educativas

\section{El estado de alarma en España}

Atendiendo a la Organización Mundial de la Salud³ que añade: "La OMS busca mejorar su colaboración con los Estados Miembros y otros interesados para reducir al mínimo el sufrimiento y las muertes en dichas situaciones. Ayuda también a las comunidades y autoridades nacionales a prepararse para las crisis y a mitigar sus efectos". Por tanto, España adoptó una serie de medidas basadas principalmente en la Ley Orgánica 4/1981, de 1 de junio, de los estados de alarma, excepción y sitio ${ }^{4}$, en su artículo cuarto que señala en su párrafo b) señala : "Crisis sanitarias, tales como epidemias y situaciones de contaminación grave y en su párrafo d) manifiesta Situaciones de desabastecimiento de productos de primera necesidad", al hilo como mencionan los autores Vidal y Delgado ${ }^{5}$ : "porque se ha producido, pero sobre todo forzada Ley Orgánica 4/1981, de 1 de junio, de los estados de alarma, Excepción y Sitio". Por lo tanto, es una norma obligatoria cuando concurran estas circunstancias, como el estado de alarma por el Covit-19. Por lo que, el Gobierno Español acaba de publicar el Real Decreto 463/2020 de 14 de marzo, por el que se declara el estado de alarma para la gestión de la situación de crisis sanitaria ocasionada por el Covit-196 cuyo artículo 1 señala: " Al amparo de lo dispuesto en el artículo cuarto, apartados b) y d) de la Ley Orgánica 4/1981 de 1 de junio, de los estados de alarma, excepción y sitio, se declara el estado de alarma con el fin de afrontar la situación de emergencia sanitaria provocada por el coronavirus COVID-19". Por lo tanto, el legislador español se reafirmó, en una norma como elemento de protección ciudadana que ya existía en el Ordenamiento Jurídico Español.

\section{El ámbito de la aplicación en materia de sanidad del Real Decreto 463/2020}

Como muy bien señala el Real Decreto 463/2020 de 14 de marzo, por el que se declara el estado de alarma para la gestión de la situación de crisis sanitaria ocasionada por el Covid-197 cuyo artículo 2 señala: "La declaración de estado de alarma afecta a todo el territorio nacional". Lo que implica que se suspenderán las facultades de las Comunidades Autónomas entre uno de ellos el sistema sanitario que está en la Constitución Española de 1978 en su artículo $148.12^{2} 21^{8}{ }^{8}$ señala: "Las Comunidades Autónomas podrá asumir las competencias: Sanidad" Por lo que, ante la pandemia del Covid-19, esto queda realmente en suspensión. Por lo cual, analizando el Real Decreto 463/2020 de 14 de marzo, por el que se declara el estado de alarma para la gestión de la situación de crisis sanitaria ocasionada por el Covid-199 en su artículo 4.1.2. c) señala las autoridades serán competentes: "A los efectos del estado de alarma, autoridad competente será el gobierno. Para el ejercicio de estas funciones a que se hace referencia en este real decreto, bajo la superior dirección del presidente del Gobierno serán las autoridades competentes delegadas, en sus respectivas áreas de responsabilidad: el Ministro de Sanidad. Ante esta situación, ¿̇qué pasará con los extranjeros en situación irregular en España respecto a su sanidad?, puesto que no queda realmente contemplado en este Real Decreto 463/2020 de 14 de marzo, por lo que se tendrá que acudir a la Ley Orgánica 4/2000, de 11 de enero, sobre derechos y libertades de los extranjeros en España y su integración social ${ }^{10}$ donde queda muy explícito en su artículo 1 al señalar: "Se considerarán extranjeros, a los efectos de la aplicación de la presente Ley, a los que carezcan de la nacionalidad española." y, su artículo 2.bis ${ }^{11}$ señala: 
"Todas las Administraciones Públicas basarán el ejercicio de sus competencias vinculadas con la inmigración en el respeto a los siguientes principios: la igualdad de Seguridad Social"., al hilo cabe mencionar el artículo $14{ }^{12}$ de la misma norma que señala: "Los extranjeros residentes tienen derecho a acceder a las prestaciones y servicios de la Seguridad Social en las mismas condiciones que los españoles Los extranjeros, cualquiera que sea su situación administrativa, tienen derecho a los servicios y prestaciones sociales básicas" , al hilo cabe mencionar el artículo $43.1^{13}$ de la Constitución Española que señala: " Se reconoce el derecho a la protección de la salud", por lo cual, una vez suspendida la sanidad autonómica los inmigrantes irregulares y, siempre que los inmigrantes irregulares estén empadronados en su municipio o, ciudad y figuren empadronados un tiempo como menciona la autora Sobrino ${ }^{14}$ que manifiesta: "el requisito de la inscripción en el municipio de residencia habitual por el empadronamiento en el municipio correspondiente al "domicilio habitual", por lo que estos quedarán a disposición del Ministro de Sanidad, por lo cual, debería considerarse la tarjeta de salud o, S.I.P., igual que a los nacionales de España.

\section{Las funciones del Ministro de Sanidad}

En este sentido, como manifiesta el Real Decreto 463/2020 de 14 de marzo, por el que se declara el estado de alarma para la gestión de la situación de crisis sanitaria ocasionada por el Covid-19 $19^{15}$ en su artículo 13 manifiesta: “El Ministro de Sanidad podrá: a) Impartir las órdenes necesarias para asegurar el abastecimiento del mercado y el funcionamiento de los servicios de los centros de producción afectados por el desabastecimiento de productos necesarios para la protección de la salud pública. b) Intervenir y ocupar transitoriamente industrias, fábricas, talleres, explotaciones o locales de cualquier naturaleza, incluidos los centros, servicios y establecimientos sanitarios de titularidad privada, así como aquellos que desarrollen su actividad en el sector farmacéutico. c) Practicar requisas temporales de todo tipo de bienes e imponer prestaciones personales obligatorias en aquellos casos en que resulte necesario para la adecuada protección de la salud pública, en el contexto de esta crisis sanitaria". Por lo que, tendrá que acudir el ministro de sanidad a las fuerzas de Seguridad del Estado es un claro ejemplo como publica un periódico español ${ }^{16}$ al señalar: "La guardia civil interviene 11.000 mascarillas quirúrgicas en el Aeropuerto de Canarias", No es que las mascarillas sean delito, sino que es requieren en este momento para los hospitales $y$, enfermos de coronavirus. Por otra parte, también es muy explícito el Real Decreto 463/2020 de 14 de marzo, por el que se declara el estado de alarma para la gestión de la situación de crisis sanitaria ocasionada por el Covid-19 en su artículo $12^{17}$ al mencionar: "Todas las autoridades civiles sanitarias de las administraciones públicas del territorio nacional, así como los demás funcionarios y trabajadores al servicio de las mismas, quedarán bajo las órdenes directas del Ministro de Sanidad en cuanto sea necesario para la protección de personas, bienes y lugares, pudiendo imponerles servicios extraordinarios por su duración o por su naturaleza. 2. Sin perjuicio de lo anterior, las administraciones públicas autonómicas y locales mantendrán la gestión, dentro de su ámbito de competencia, de los correspondientes servicios sanitarios, asegurando en todo momento su adecuado funcionamiento. El Ministro de Sanidad se reserva el ejercicio de cuantas facultades resulten necesarias para garantizar la cohesión y equidad en la prestación del referido servicio. 3. En especial, se asegurará la plena disposición de las autoridades civiles responsables del ámbito de salud pública, y de los empleados que presten servicio en el mismo. 4. Estas medidas también garantizarán la posibilidad de determinar la mejor distribución en el territorio de todos los medios técnicos y personales, 
de acuerdo con las necesidades que se pongan de manifiesto en la gestión de esta crisis sanitaria. 5. Las autoridades competentes delegadas ejercerán sus facultades a fin de asegurar que el personal y los centros y establecimiento sanitarios de carácter militar contribuyan a reforzar el Sistema Nacional de Salud en todo el territorio nacional. 6. Asimismo, el Ministro de Sanidad podrá ejercer aquellas facultades que resulten necesarias a estos efectos respecto de los centros, servicios y establecimientos sanitarios de titularidad privada.". Por lo tanto, la Sanidad Pública y privada y las Comunidades Autónomas y Locales estarán bajo las órdenes del Ministro de Sanidad que a su vez dependen del Gobierno Central, en cuanto la distribución de los medios técnicos o, médicos.

5 El ámbito de aplicación en materia de interior ante los extranjeros irregulares respecto al real decreto ley 463/2020

Al respecto, como muy bien señala Real Decreto 463/2020 de 14 de marzo, por el que se declara el estado de alarma para la gestión de la situación de crisis sanitaria ocasionada por el Covid-19 18 en su artículo 4 b). 3. "El ministro de interior. Los actos, disposiciones y medidas a que se refiere el párrafo anterior podrán adoptarse de oficio o a solicitud motivada de las autoridades autonómicas y locales competentes, de acuerdo con la legislación aplicable en cada caso Para ello, no será precisa la tramitación de procedimiento administrativo alguno.". Lo que implica que el ministro de interior no necesita ninguna actuación espacial pues puede actuar de oficio, aunque las distintas Comunidades Autónomas y locales podrán motivar su actuación. Por tanto, si un extranjero irregular con domicilio habitual, las distintas fuerzas públicas le piden documentación y, solo tiene pasaporte, ¿qué le ocurriría? Como bien señala la Ley Orgánica 4/2000, de 11 de enero, sobre derechos y libertades de los extranjeros en España y su integración social en su artículo 2.bis ${ }^{19} \mathrm{~g}$ señala : "la lucha contra la inmigración irregular", al hilo cabe mencionar la Ley Orgánica 2/2009, de 11 de diciembre, de reforma de la Ley Orgánica 4/2000, de 11 de enero, sobre derechos y libertades de los extranjeros en España y su integración social ${ }^{20}$ al señalar en su artículo 2 ter Seis ${ }^{21}$ artículo 4.1 : "Los extranjeros que se encuentren en territorio español tienen el derecho y el deber de conservar la documentación que acredite su identidad, expedida por las autoridades competentes del país de origen o de procedencia, así como la que acredite su situación en España". Por lo cual, tiene que acreditar su situación en España, procediéndose a su expulsión, si están en situación irregular. Por otro lado, el legislador español se contradice cuando en la misma norma jurídica señala 2 ter Catorce $121^{22}$ : "Los extranjeros que se encuentren en España, inscritos en el padrón del municipio en el que tengan su domicilio habitual, tienen derecho a la asistencia sanitaria en las mismas condiciones que los españoles". Por lo que, no se debería decretar su expulsión del territorio nacional, sino integrarlos, siempre que no sean personas delictivas o, hubiesen cometido algún delito. Por lo que, en si no debería ser el Real Decreto 463/2020 de 14 de marzo, por el que se declara el estado de alarma para la gestión de la situación de crisis sanitaria ocasionada por el Covid-19, una Ley de Policía ante este colectivo.

5.1 El ámbito de aplicación en materia de interior ante españoles y extranjeros legales respecto al real decreto ley 463/2020

Respecto a los españoles y, extranjeros residentes legalmente en España, como se ha visto en el Real Decreto 463/2020 de 14 de marzo, por el que se declara el estado de 
alarma para la gestión de la situación de crisis sanitaria ocasionada por el Covid-19 ${ }^{23}$ como señala el artículo 4.b).3 in fine: "El ministro de interior. Los actos, disposiciones y medidas a que se refiere el párrafo anterior podrán adoptarse de oficio o a solicitud motivada de las autoridades autonómicas y locales competentes, de acuerdo con la legislación aplicable en cada caso y deberán prestar atención a las personas vulnerables. Para ello, no será precisa la tramitación de procedimiento administrativo alguno". Como muy bien se refiere el ministro del interior protegerá por medio de este Real Decreto Ley a las personas más vulnerables contra esta pandemia del Covti-19, entre otros a las personas mayores que sufren patologías múltiples, personas con patologías múltiples, niños y niñas y demás ciudadanos así cabe citar los autores Uribe y González ${ }^{24}$ que mencionan: "Se afecta un derecho fundamental (el derecho a la salud)", al hilo cabe mencionar la Sentencia del Tribunal Supremo Español ${ }^{25}$ en sus Fundamentos de derecho cuarto.1 señala: " situación de vulnerabilidad personas con discapacidad, personas de edad avanzada, menores de edad", por lo tanto este factor de riesgo entrarían estos colectivos, incluidas las personas enfermas con múltiples patologías.

\section{6 ¿Como actuará el ministro del interior ante el covd-10?}

Por lo que, el Real Decreto 463/2020 de 14 de marzo, por el que se declara el estado de alarma para la gestión de la situación de crisis sanitaria ocasionada por el Covid$19^{26}$ en su artículo 5 señala: "Los integrantes de las Fuerzas y Cuerpos de Seguridad del Estado, los Cuerpos de Policía de las comunidades autónomas y de las corporaciones locales quedarán bajo las órdenes directas del Ministro del Interior, a los efectos de este real decreto, en cuanto sea necesario para la protección de personas, bienes y lugares, pudiendo imponerles servicios extraordinarios por su duración o por su naturaleza. Los agentes de la autoridad podrán practicar las comprobaciones en las personas, bienes, vehículos, locales y establecimientos que sean necesarias para comprobar y, en su caso, impedir que se lleven a cabo los servicios y actividades suspendidas en este real decreto, salvo las expresamente exceptuadas. Para ello, podrán dictar las órdenes y prohibiciones necesarias y suspender las actividades o servicios que se estén llevando a cabo. A tal fin, la ciudadanía tiene el deber de colaborar y no obstaculizar la labor de los agentes de la autoridad en el ejercicio de sus funciones". Lo que implica requisas de bienes o, las personas que obstaculice a las fuerzas armadas o cuerpos de seguridad la imposición de multa o, prisión. Por lo tanto, será aplicable Ley 33/2011, de 4 de octubre, General de Salud Pública ${ }^{27}$ que en su artículo 57b) señala: "b) Son infracciones graves: 1. La realización de conductas u omisiones que puedan producir un riesgo o un daño grave para la salud de la población, cuando ésta no sea constitutiva de infracción muy grave. 2.으 La denegación de apoyo, auxilio o colaboración a los agentes de la autoridad sanitaria. 3. El incumplimiento de las instrucciones recibidas de la autoridad competente, si comporta daños para la salud, cuando no sea constitutivo de infracción muy grave. 4.․ La resistencia o la obstrucción de aquellas actuaciones que fueren exigibles, de acuerdo con lo previsto en esta ley. 5. El incumplimiento de comunicación de información y resto de obligaciones conforme a lo dispuesto en el Título I de esta ley, cuando revista carácter de gravedad" y, atendiendo al Título I de esta norma señala su artículo $1^{28}$ párrafo 2 o lo siguiente: "La salud pública es el conjunto de actividades organizadas por las Administraciones públicas, con la participación de la sociedad, para prevenir la enfermedad así como para proteger, promover y recuperar la salud de las personas, tanto en el ámbito individual como en el colectivo y mediante acciones sanitarias, sectoriales y transversales". Por tanto, el gobierno español a efectos de su representante el ministro del interior podrá efectuar las presentes sanciones a través de 
la fuerzas armadas y cuerpos de seguridad, policías autonómicos y locales, para preservar la Salud Pública de los ciudadanos y ciudadanas frente a la pandemia del Covid-19.

6.1 ¿Qué tipo de sanciones aplicará a los ciudadanos que incumplan las fuerzas de seguridad y cuerpos del estado?

Atendiendo a la Ley 17/2015, de 9 de julio, del Sistema Nacional de Protección $\mathrm{Civil}^{29}$ en su artículo 46 señala las sanciones administrativas que se deben aplicar ante la cuarentena de los ciudadanos y ciudadanas españolas: "1. Las infracciones muy graves se sancionarán con multa de 30.001 a 600.000 euros 2. Las infracciones graves se sancionarán con multa de 1.501 a 30.000 euros 3. Las infracciones leves se sancionarán con multa de hasta 1.500 euros", al hilo cabe mencionar ¿Quién impondrá estas sanciones administrativas? Por lo cual, se da la respuesta en la Ley 17/2015, de 9 de julio, del Sistema Nacional de Protección Civil en su artículo $48^{30}$ al señalar: "Serán competentes para la resolución de los procedimientos sancionadores: a) El titular de la Delegación del Gobierno cuando se trate de infracciones leves. b) El titular de la Dirección General de Protección Civil y Emergencias cuando se trate de infracciones graves. c) El titular del Ministerio del Interior cuando se trate de infracciones muy graves". Por lo que, en las infracciones más graves actuará el ministerio del interior y, como consecuencia los demás titulares de los distintos departamentos todos que están centralizados en el Estado. Por otro lado, cabe mencionar el Código Penal Español ${ }^{31}$ que en su artículo 550 las causas de prisión que señala: "Son reos de atentado los que acometan a la autoridad, a sus agentes o funcionarios públicos, o empleen fuerza contra ellos, lo intimiden gravemente o les hagan resistencia activa también grave, cuando se hallen ejecutando las funciones de sus cargos o con ocasión de ellas", al mismo tiempo y siguiendo, con el Código Penal Español en su artículo $551.1^{32}$ señala prisión para los que atenten a las fuerzas armadas y cuerpos de seguridad de España: "Los atentados comprometidos en el artículo anterior será castigados con penas de prisión de dos a cuatro años y multa de tres meses a seis meses si el atentado fuera contra la autoridad y de prisión para los demás casos". Por lo que, la normativa del Código Penal Español se aplicará en estos casos ejemplo: "Denunciado por toser adrede en la cara de un policía. La policía nacional ha denunciado por desobediencia a un hombre de 37 años que el pasado domingo, cuando ya estaba vigente el estado de alarma por coronavirus, se acercó a un agente que custodiaba el edificio de la Delegación del Gobierno en Cataluña y le tosió adrede y de forma repetitiva a la cara ${ }^{33 "}$. En este último de los casos sería la denuncia de oficio ante el juzgado, por considerarse delito.

\subsection{La protección del ministro del interior ante los reos en las carceles por el covid-19}

Al respecto, la Orden INT/227/2020, de 15 de marzo, en relación con las medidas que se adoptan en el ámbito de Instituciones Penitenciarias al amparo del Real Decreto 463/2020, de 14 de marzo, por el que se declara el estado de alarma para la gestión de la situación de crisis sanitaria ocasionada por el COVID-19 ${ }^{34}$ señala en su artículo primero: " Durante la vigencia del estado de alarma declarado por el Real Decreto 463/2020, de 14 de marzo, para la gestión de la situación de crisis sanitaria ocasionada por el COVID-19 ${ }^{35}$, se adoptan las siguientes medidas en relación con los internos de todos los centros penitenciarios del Estado: a) Se suspenden todas las comunicaciones ordinarias de los internos en los centros penitenciarios, dada la limitación de la libertad de circulación que tienen tanto los internos como las familias y amigos que les visitan. b) Se suspenden las salidas de permiso, salidas programadas y cualquier otra salida, salvo por causas de fuerza

13 | Revista Brasileira de Direito Animal, e-issn: 2317-4552, Salvador, volume 15, n. 01, p.7-24, Jan-Abril 2020 
mayor o situación de necesidad para evitar los desplazamientos que están prohibidos por el artículo 7 del Real Decreto 463/2020, de 14 de marzo. c) Los internos clasificados en tercer grado o que tengan aplicado el régimen de flexibilidad que se hallen destinados en centros de inserción social, secciones abiertas o centros ordinarios podrán salir para la realización de las actividades expresamente relacionadas en el artículo 7 del mencionado real decreto, adoptándose los protocolos establecidos cuando regresen al centro penitenciario. En todo caso, en cualquier desplazamiento deberán respetarse las recomendaciones y obligaciones dictadas por las autoridades sanitarias". Por lo cual, se suspenderá la vis a vis entre los reos y familiares, y los internos de tercer grado se adaptarán a lo que menciona el artículo 7 .1. c.d. del Real Decreto463/2020, de 14 de marzo ${ }^{36}$ que señala: "Durante la vigencia del estado de alarma las personas únicamente podrán circular por las vías de uso público para la realización de las siguientes actividades: Desplazamiento al lugar de trabajo para efectuar su prestación laboral, profesional o empresarial. Retorno al lugar de residencia habitual.". Por lo cual, los presos de tercer grado se dirigirán al lugar de trabajo asignado y. el retorna a la prisión

7 Las limitaciones de los ciudadanos españoles ante el Real Decreto 463/2020 de 14 de marzo, por el que se declara el estado de alarma en España

Al respecto, como menciona el Real Decreto 463/2020 de 14 de marzo, por el que se declara el estado de alarma para la gestión de la situación de crisis sanitaria ocasionada por el Covid-19 ${ }^{37}$ en su artículo 7 manifiesta: "Durante la vigencia del estado de alarma las personas únicamente podrán circular por las vías o espacios de usos público para la realización de las siguientes actividades, que deberán de realizarse individualmente, salvo que se acompañe a personas con discapacidad, menores, mayores o por causa justificada ${ }^{38}$ : a) Adquisición de alimentos, productos farmacéuticos y de primera necesidad. b) Asistencia a centros, servicios y establecimientos sanitarios .c) Desplazamiento al lugar de trabajo para efectuar su prestación laboral, profesional o empresarial. d) Retorno al lugar de residencia habitual. e) Asistencia y cuidado a mayores, menores, dependientes, personas con discapacidad o personas especialmente vulnerables. f) Desplazamiento a entidades financieras y de seguros. g) Por causa de fuerza mayor o situación de necesidad. h) Cualquier otra actividad de análoga naturaleza que habrá de hacerse individualmente, salvo que se acompañe a personas con discapacidad o por otra causa justificada. 2. Igualmente, se permitirá la circulación de vehículos particulares por las vías de uso público para la realización de las actividades referidas en el apartado anterior o para el repostaje en gasolineras o estaciones de servicio. 3. En todo caso, en cualquier desplazamiento deberán respetarse las recomendaciones y obligaciones dictadas por las autoridades sanitarias. 4. El Ministro del Interior podrá acordar el cierre a la circulación de carreteras o tramos de ellas por razones de salud pública, seguridad o fluidez del tráfico o la restricción en ellas del acceso de determinados vehículos por los mismos motivos. Cuando las medidas a las que se refieren los párrafos anteriores se adopten de oficio se informará previamente a las administraciones autonómicas que ejercen competencias de ejecución de la legislación del Estado en materia de tráfico, circulación de vehículos y seguridad vial. Las autoridades estatales, autonómicas y locales competentes en materia de tráfico, circulación de vehículos y seguridad vial garantizarán la divulgación entre la población de las medidas que puedan afectar al tráfico rodado". Por tanto, es una fiel copia de la Ley Orgánica 4/1981, de 1 de junio, de los estados de alarma, excepción y sitio ${ }^{39}$ como manifiesta su artículo 11.1 al señalar: "Limitar la circulación o permanencia de personas o vehículos en horas y lugares determinados, o condicionarlas al cumplimiento de ciertos requisitos". Por otro lado, el 
nuevo Real Decreto 463/2000, de 14 de marzo no deja fuera de este ámbito a otras autoridades como. "las autoridades estatales, autonómicas y locales sobre materia de tráfico.". Por tanto, siempre atendiendo la figura del ministro del interior, como elemento principal coordinando desde el gobierno central. Por otra parte, Real Decreto 463/2020 de 14 de marzo, por el que se declara el estado de alarma para la gestión de la situación de crisis sanitaria ocasionada por el Covid-1940 en su artículo 11 señala: "la posibilidad de respetar la distancia entre ellos de, al menos, un metro", por lo que cuando vayan o estén parados los ciudadanos deben estar separados por lo menos un metro de distancia tanto en la calle 0 , a la espera de los supermercados y entrar de uno en uno.

8 Las funciones de la Ministra de Defensa y el Ministro de Transportes en el Real Decreto 463/2020 de 14 de marzo, por el que se declara el estado de alarma en España

En este sentido, como muy bien queda redactado en Real Decreto 463/2020 de 14 de marzo, por el que se declara el estado de alarma para la gestión de la situación de crisis sanitaria ocasionada por el Covid-19 ${ }^{41}$ como manifiesta el artículo 15.2 "Asimismo, las autoridades competentes podrán acordar la intervención de empresas o servicios, así como la movilización de las Fuerzas y Cuerpos de Seguridad del Estado y de las Fuerzas Armadas con el fin de asegurar el buen funcionamiento de lo dispuesto en el presente artículo", respecto al suministro de alimentos de primera necesidad, creación de hospitales de campaña como es el caso de la Unidad de Emergencias Militar o, el control de medios de transporte, y las personas que circulan por las vías públicas como bien menciona la Instrucción de 15 de marzo de 2020, del Ministerio de Defensa, por la que se establecen medidas para la gestión de la situación de crisis sanitaria ocasionada por el COVID-19 en el ámbito del Ministerio de Defensa ${ }^{42}$, al respecto, en su apartado segundo señala: "b) Poner a disposición de la autoridad competente, así como de las autoridades competentes delegadas las capacidades militares de la Unidad Militar de Emergencias, así como aquellas otras capacidades de las Fuerzas Armadas y del Ministerio de Defensa, al menos, en materia de: - Policía Militar. - Transporte logístico terrestre. - Aerotransporte general y capacidades de aerotransporte medicalizado. - Control de tráfico aéreo, de la navegación marítima, puertos y aeropuertos. - Alojamientos logísticos y establecimiento de campamentos militares. - El ámbito de la Inspección General de Sanidad de la Defensa. e) El personal de la red sanitaria militar estará en disposición de incorporarse a su destino tan pronto sea requerido por la autoridad competente del Ministerio de Defensa. f) El personal de la red sanitaria militar se considera de carácter crítico y reducirá los permisos al mínimo imprescindible, debiendo ser autorizada, por el Subsecretario de Defensa o Inspector General de Sanidad de la Defensa, cualquier excepción", y siguiendo en el apartado cuarto de la norma ${ }^{43}$ señala: "Se respetarán en todo caso las recomendaciones e instrucciones de las autoridades sanitarias civiles y militares para la prevención de la transmisión del COVID19. A tal efecto, el personal incluido en el ámbito de aplicación de esta instrucción utilizará, en todo caso, los equipos de trabajo adecuados para garantizar su seguridad sanitaria atendiendo a estos efectos a lo que se disponga por el Ministerio de Sanidad", por lo que no es solamente protección de fronteras sino que también actuará como médicos y creación de hospitales como menciona el Periódico el Mundo ${ }^{44}$ :" Las Fuerzas Armadas reforzarán las tareas de traslados de fallecidos tras un acuerdo entre el Gobierno regional y el Ministerio de Defensa". Por otra parte de debe recordar que también el ejército está compuesto por la guardia civil y la policía nacional que dependen del Ministerio del Interior serán las encargadas de vigilar las fronteras así cabe mencionar el Real Decreto 463/2020 
de 14 de marzo, por el que se declara el estado de alarma para la gestión de la situación de crisis sanitaria ocasionada por el Covid- $19^{45}$ en su artículo 16 que señala: "Las autoridades competentes delegadas adoptarán las medidas necesarias para garantizar el tránsito aduanero en los puntos de entrada o puntos de inspección fronteriza ubicados en puertos o aeropuertos. A este respecto se atenderá de manera prioritaria los productos que sean de primera necesidad". Por lo cual, velarán por los productos más necesarios para la sociedad española. Respecto a las funciones del Ministro de Transportes como muy bien se expresa el Real Decreto 463/2020 de 14 de marzo, por el que se declara el estado de alarma para la gestión de la situación de crisis sanitaria ocasionada por el Covid-19 ${ }^{46}$ en su artículo 14 manifiesta: "En relación con todos los medios de transporte, cualquiera que sea la Administración competente sobre los mismos, se aplicará lo siguiente: a) El Ministro de Transportes, Movilidad y Agenda Urbana queda habilitado para dictar los actos y disposiciones que, en la esfera específica de su actuación, sean necesarios para establecer condiciones a los servicios de movilidad, ordinarios o extraordinarios, en orden a la protección de personas, bienes y lugares.2.Asimismo, se adoptan las siguientes medidas aplicables al transporte interior: a) En los servicios de transporte público de viajeros por carretera, ferroviarios, aéreo y marítimo que no están sometidos a contrato público u obligaciones de servicio público (OSP), los operadores de transporte reducirán la oferta total de operaciones en, al menos, un 50 \%. Por resolución del Ministro de Transportes, Movilidad y Agenda Urbana se podrá modificar este porcentaje y establecer condiciones específicas al respecto", por lo cual el Ministro de Transportes podrá modificar las reducciones de transportes ferroviarios y, por carretera.

\subsection{Los transportes por carrereta en españa durante la cuarentena por el covid-19}

Al respecto, ante la necesidad de alimentos y otros productos de primera necesidad en todo el territorio nacional, por el que se encarga el ministro de transportes se dictó la Orden TMA/229/2020, de 15 de marzo, por la que dictan disposiciones respecto al acceso de los transportistas profesionales a determinados servicios necesarios para facilitar el transporte de mercancías en el territorio nacional ${ }^{47}$, mediante su artículo uno señala: "Los establecimientos de suministro de combustible que dispongan servicios de aseo deberán facilitar su uso a los conductores profesionales. Así mismo, los centros de carga y descarga que cuenten con este tipo de instalaciones, deberán facilitar en la medida de lo posible su uso a los conductores profesionales que realicen operaciones en ellos. Las medidas que se puedan exigir a los conductores para el acceso a este tipo de instalaciones seguirán los criterios e instrucciones de prevención que con carácter general establezca el Ministerio de Sanidad, o las que dicho órgano pudiera establecer específicamente en este ámbito. Asimismo, con objeto de posibilitar los descansos adecuados en cumplimiento de la normativa de tiempos de conducción y descanso, que son imprescindibles para poder llevar a cabo las operaciones de transporte, aquellos establecimientos que dispongan de cocina, servicios de restauración, o expendedores de comida preparada, deberán facilitar al transportista profesional un servicio de catering". Por lo cual el Ministerio de Transportes da unas directrices a los profesionales de la conducción para que realicen su trabajo y, sean atendidos mediante un catering de comidas y de descanso mientras realizan su labor de transportes.

\section{Transito aduanero en el estado de alarma por el Covid-19 en España}


Al respecto, del tránsito de aduanas las competencias recaerán sobre el Ministro de Interior, aunque el Real Decreto 463/2020 de 14 de marzo, por el que se declara el estado de alarma para la gestión de la situación de crisis sanitaria ocasionada por el Covid-19 ${ }^{48}$, no expresa quien tendrá competencias así su artículo 16 señala: "Las autoridades competentes delegadas adoptarán las medidas necesarias para garantizar el tránsito aduanero en los puntos de entrada o puntos de inspección fronteriza ubicados en puertos o aeropuertos. A este respecto se atenderá de manera prioritaria los productos que sean de primera necesidad" al hilo, cabe mencionar la Orden Int/ 248/2020, de 16 de marzo, por la que se establecen criterios de actuación para las Fuerzas y Cuerpos de Seguridad ante el restablecimiento temporal de controles fronterizos, ${ }^{49}$ que señala en su artículo 2: "El restablecimiento temporal de los controles en las fronteras interiores se aplicará en todas las fronteras interiores terrestres, y será efectivo desde las 00:00 horas del 17 de marzo de 2020 hasta las 24:00 horas del 26 de marzo de 2020. Durante su vigencia, así como durante el resto del tiempo por el que, en su caso, se mantengan los controles fronterizos, se activarán las siguientes medidas. 2. Solo se permitirá la entrada a territorio nacional, por vía terrestre, a las siguientes personas: a) Ciudadanos españoles. b) Residentes en España. c) Trabajadores transfronterizos. d) Aquellas que acrediten documentalmente causas de fuerza mayor o situación de necesidad. 3. Queda exceptuado de estas restricciones el personal extranjero acreditado como miembro de las misiones diplomáticas, oficinas consulares y organismos internacionales sitos en España, siempre que se trate de desplazamientos vinculados al desempeño de funciones oficiales. 4. Con el fin de asegurar la continuidad de la actividad económica y de preservar la cadena de abastecimiento, estas medidas no son aplicables al transporte de mercancías. 5. Las Direcciones Generales de la Policía y de la Guardia Civil adoptarán cuantas medidas operativas y organizativas sean necesarias para el buen fin de lo dispuesto en la presente Orden de acuerdo con sus respectivos ámbitos competenciales". Por tanto, España cierra las fronteras terrestres entre España y Francia y, las demás fronteras de Gibraltar y Andorra actuarán como siempre habían actuado respecto a los trabajadores transfronterizos. ¿Quiénes podrán entrar en España? Como expresa la norma el artículo 16.2 "Ciudadanos españoles, Residentes en España, Trabajadores transfronterizos en el caso que tengan residencia en España y trabajen en los países cercanos de la Unión Europea y, las personas que siempre acrediten que tienen una fuerza mayor para pasar a España quedando exceptuado las misiones diplomáticas, en este caso opino que el legislador español debería haber pensado que este tipo de misiones se deberían hacer por vía telemática o, videoconferencia. Al mismo tiempo, es un cierre parcial de fronteras puesto que se permite a los transportes el abastecimiento de productos entre los países. Por otra parte, se admite quienes operarán serán la Guardia Civil que depende de la Ministra de Defensa y, la Policía Nacional que depende del Ministro del Interior. Por otro lado, se suspenden los vuelos directos de España con Italia asimismo los cruceros como señala la Orden PCM/205/2020, de 10 de marzo, por la que se publica el Acuerdo del Consejo de Ministros de 10 de marzo de 2020, por el que se establecen medidas excepcionales para limitar la propagación y el contagio por el COVID-19, mediante la prohibición de los vuelos directos entre la República italiana y los aeropuertos españoles ${ }^{50}$ en su artículo Primero: " Se prohíbe la realización de vuelos directos desde cualquier aeropuerto situado en la República de Italia a cualquier aeropuerto situado en el Reino de España a partir de las 00:00 horas del día 11 de marzo de 2020 y hasta las 00:00 horas del día 25 de marzo de 2020", por lo cual, si un avión realiza una escala en otro país el ciudadano proveniente de Italia podrán entrar en España lo cual fue un fallo del legislador y, siguiendo con la misma norma en su artículo segundo manifiesta: "Esta prohibición no será de aplicación a las aeronaves de Estado, ni a la 
realización de escalas con fines no comerciales, vuelos exclusivos de carga, vuelos posicionales, humanitarios, médicos o de emergencia". Por lo que, esta disposición no afectará a los vuelos estatales, de carga o, humanitarios. Por otro lado, la Orden PCM/216/2020, de 12 de marzo, por la que se publica el Acuerdo del Consejo de Ministros de 12 de marzo de 2020, por el que se establecen medidas excepcionales para limitar la propagación y el contagio por el COVID-19, mediante la prohibición de entrada de buques de pasaje procedentes de la República italiana y de cruceros de cualquier origen con destino a puertos españoles ${ }^{51}$, en sus artículos siguientes señala en su artículo primero "Se prohíbe la entrada en los puertos españoles a los buques de pasaje de transbordo rodado y buques de pasaje que presten servicio de línea regular entre puertos de la República de Italia y el Reino de España que hayan embarcado pasajeros en puerto italiano. Se prohíbe la entrada en puertos españoles de los buques de pasaje tipo crucero procedentes de cualquier puerto" y su artículo cuarto ${ }^{52}$ menciona: "Esta prohibición no será de aplicación a los buques de Estado, a los buques que transporten carga exclusivamente ni a los buques que realicen navegaciones con fines humanitarios, médicos o de emergencia. El Ministerio de Sanidad podrá excepcionalmente levantar las prohibiciones a los buques, que deberán ser autorizados. En todo caso se adoptarán todas las medidas necesarias de control sanitario para evitar que supongan un riesgo para la población de nuestro país". Por lo cual, no podrán entrar cruceros 0 , buques procedentes de Italia $y$, al mismo tiempo cualquier buque que proceda del cualquier país, exceptuando buques de carga 0 , con fines de carácter sanitario, siempre bajo la supervisión del ministerio de Sanidad.

\section{La suspensión de los estudios durante el estado de alarma en España}

A todo esto, cabe mencionar el Real Decreto 463/2020 de 14 de marzo, por el que se declara el estado de alarma para la gestión de la situación de crisis sanitaria ocasionada por el Covid-1953 en su artículo 9 señala: "Se suspende la actividad educativa presencial en todos los centros y etapas, ciclos, grados, cursos y niveles de enseñanza contemplados en el artículo 3 de la Ley Orgánica 2/2006, de 3 de mayo, de Educación, incluida la enseñanza universitaria, así como cualesquiera otras actividades educativas o de formación impartidas en otros centros públicos o privados. Durante el período de suspensión se mantendrán las actividades educativas a través de las modalidades a distancia y "on line», siempre que resulte posible.". Por lo cual, todos los niveles educativos utilizarán la modalidad "on line" o, que es lo mismo mediante internet, ratificándolo Ley Orgánica 2/2006, de 3 de mayo, de Educación $n^{54}$ en su artículo $3 . .9$ que señala: "Para garantizar el derecho a la educación de quienes no puedan asistir de modo regular a los centros docentes, se desarrollará una oferta adecuada de educación a distancia o, en su caso, de apoyo y atención educativa específica2, atendiendo a todas las modalidades educativas e incluso universitarias.

\section{Conclusiones}

$1^{\circ}$ Ante la proliferación de la pandemia del Covid-19 en España, después de Italia y China el Gobierno Español Decreto el estado de alarma y el confinamiento en sus domicilios de primera residencia a todos los ciudadanos y ciudadanas españolas, en sus casas limitando así ciertos Derechos Fundamentales que están en la Constitución Española de 1978, Pudiéndose alargar el Real Decreto Ley 464/2020, según la proliferación de la pandemia del Civid-19 en España, por medio del Congreso de Diputados. 
$2^{\circ}$ El Real Decreto Ley 464/2020, no aclara la situación respecto a los inmigrantes irregulares en España, que tengan residencia habitual en España, puesto que el Sistema de Sanidad Español cada Comunidad Autónoma se rige en este sentido por su legislación particular, colocando en tela de juicio si este colectivo en estos momentos depende del Gobierno Central Español, lo que se debería modificar la Ley de extranjería española para poderlos legalizar en este momento.

$3^{\circ}$ Las restricciones de salir de casa abarcan desde las sanciones administrativas hasta el ámbito Penal conllevando la pena de cárcel, a todos los que incumplan el Real Decreto Ley 464/20020.

$4^{\circ}$ Las distancias de las personas al circular en las calles o, vías serán de un metro como mínimo incluso en los supermercados, o estancos $u$ otros locales que permite la norma. Los menores pueden salir acompañados, con su padre incluso personas dependientes.

$5^{\circ}$ Las Fuerzas armadas colaborarán en la construcción de hospitales y, sus médicos como la Unidad Militar de Emergencias, los demás militares, Policía Nacional y Policía local se de dedicarán a contralar a los ciudadanos y ciudadanas, tanto los que salen a calle, vehículos, y demás medios de trasportes para que observen las medidas impuestas por el Gobierno Español, que están a cargo de sus respectivos ministros elegidos por el ejecutivo.

$6^{\circ}$ Se prohíbe el vi a vis de los presos en los centros penitenciarios y, los presos que están en tercer grado después de sus salidas vuelvan a sus centros penitenciarios.

$7^{\circ} \mathrm{El}$ cierre de fronteras es fuero interno de cada Estado miembro de cada Estado que pertenece a la Unión Europea, solamente dejando pasara a España los trabajadores transfronterizos, ciudadanos españoles y, casos excepcionales. Por otra parte, es digno de criticar puesto que esta norma debería haberse hecho muy anteriormente por parte del Gobierno Español.

$8^{\circ}$ También se prohíben el tráfico aéreo entre el Reino de España y la República Italiana, del mismo modo los cruceros que provengan de Italia u, otros países excepto los buques de carga, humanitarios en este último caso el legislador español indirectamente hace referencia a los inmigrantes de las pateras 0 , de alta mar y por último a los buques, médicos.

$9^{\circ}$ Respecto a la prohibición de los cruceros provenientes de Italia u, otros países el legislador español promulgo la ley demasiado tarde lo que implico que parte de la pandemia del Covid-19, se extendiera a España.

$10^{\circ} \mathrm{El}$ cierre de Centros Educativos o, Universitarios por lo que es un elemento de contingencia conta el Covid-19 aplicándose los estudios "on line".

$11^{\circ} \mathrm{El}$ gobierno a través del Ministerio de Sanidad se debería hacer responsable de las Residencias de Personas Mayores, donde actualmente fallecen muchos mayores a causas del Covid-19, al mismo tiempo actuando dentro de los centros la Unidad Militar de Emergencias, no solamente en la desinfección de los centros neurálgicos o, calles, dependiendo estos últimos de la ministra de defensa.

\section{Notas de referencia}

\footnotetext{
${ }^{1}$ Constitución Española y la Constitución Europea (2006). Edición Especial Consejo General de la Abogacía Española Editorial La Ley Madrid (Las Rozas). p .45.
} 
2 Tribunal Constitucional (Pleno) (Ponente: Batarrita Asua, Adela) (Sentencia núm.83/2016 de 28 de abril). RTC.2016 83

${ }^{3}$ Organización Mundial de la Salud. p.1. who.int/hac/crises/es

${ }^{4}$ Ley Orgánica 4/1981, de 1 de junio, de los estados de alarma, excepción y sitio. Jefatura del Estado. Boletín Oficial del Estado (BOE) Madrid. N. Boletín 134. BOE-A-1981-12774. p.4. https: //www.boe.es>buscar

5 Vidal Prado, Carlos y Ramos Delgado David (2011) (N.92). "Algunas consideraciones sobre declarar el estado de alarma y su prorroga". Editorial Revista Española de Derecho Constitucional CEPC.p.263

${ }^{6}$ Real Decreto 463/2020 de 14 de marzo, por el que se declara el estado de alarma para la gestión de la situación de crisis sanitaria ocasionada por el Covit-19 Jefatura del Estado. Boletín Oficial del Estado (BOE) Madrid. N. Boletín 67. p.25390. BOE-A-2020-3692.BOE.es https: //www.boe.es>buscar

${ }^{7}$ Real Decreto 463/2020 de 14 de marzo, por el que se declara el estado de alarma para la gestión de la situación de crisis sanitaria ocasionada por el Covit-19 Jefatura del Estado. Boletín Oficial del Estado (BOE) Madrid. N. Boletín 67. p.25390. BOE-A-2020-3692.BOE.es https: //www.boe.es>buscar

${ }^{8}$ Constitución Española y la Constitución Europea (2006). Op. Cit., pps.56-57.

${ }^{9}$ Real Decreto 463/2020 de 14 de marzo, por el que se declara el estado de alarma para la gestión de la situación de crisis sanitaria ocasionada por el Covit-19 Jefatura del Estado. Boletín Oficial del Estado (BOE) Madrid. N. Boletín 67. p.25391. BOE-A-2020-3692.BOE.es https: //www.boe.es>buscar<act

${ }^{10}$ Ley Orgánica 4/2000, de 11 de enero, sobre derechos y libertades de los extranjeros en España y su integración social Jefatura del Estado. Boletín Oficial del Estado (BOE) Madrid. N. Boletín 10. p.6. BOE-A-2000-554.BOE.es https: //www.boe.es>buscar>act

${ }^{11}$ Ley Orgánica 4/2000, de 11 de enero, sobre derechos y libertades de los extranjeros en España y su integración social Jefatura del Estado. Boletín Oficial del Estado (BOE) Madrid. N. Boletín 10. p.7. BOE-A-2000-554.BOE.es https: //www.boe.es>buscar>act

${ }^{12}$ Ley Orgánica 4/2000, de 11 de enero, sobre derechos y libertades de los extranjeros en España y su integración social Jefatura del Estado. Boletín Oficial del Estado (BOE) Madrid.

N. Boletín 10. p.10. BOE-A-2000-554.BOE.es https: //www.boe.es>buscar>act

${ }^{13}$ Constitución Española y la Constitución Europea (2006). Op. Cit., p.24

14 Sobrino Guijarro, Irene (2013) (Vol.3) (N2) "Inmigrantes irregulares derecho a la protección de la salud: análisis de la reforma sanitaria en España". Revista Jurídica de Derechos Sociales Editorial Universidad de Sevilla. 134.

${ }^{15}$ Real Decreto 463/2020 de 14 de marzo, por el que se declara el estado de alarma para la gestión de la situación de crisis sanitaria ocasionada por el Covit-19 Jefatura del Estado. Boletín Oficial del Estado (BOE) Madrid. N. Boletín 67. p.25390. BOE-A-2020-3692.BOE.es https: //www.boe.es>buscar

${ }^{16}$ Periódico 20 minutos. p.1.https://www.20minutos.es>noticia>la-guardia-civil-interviene11-000-m...

${ }^{17}$ Real Decreto 463/2020 de 14 de marzo, por el que se declara el estado de alarma para la gestión de la situación de crisis sanitaria ocasionada por el Covit-19 Jefatura del Estado. Boletín Oficial del Estado (BOE) Madrid. N. Boletín 67. p.25394. BOE-A-2020-3692.BOE.es https: //www.boe.es>buscar

${ }^{18}$ Real Decreto 463/2020 de 14 de marzo, por el que se declara el estado de alarma para la gestión de la situación de crisis sanitaria ocasionada por el Covit-19 Jefatura del Estado. 
Boletín Oficial del Estado (BOE) Madrid. N. Boletín 67. p.25391. BOE-A-2020-3692.BOE.es https: //www.boe.es>buscar

${ }^{19}$ Ley Orgánica 4/2000, de 11 de enero, sobre derechos y libertades de los extranjeros en España y su integración social Jefatura del Estado. Boletín Oficial del Estado (BOE) Madrid. N. Boletín 10. p.7. BOE-A-2000-554.BOE.es https: //www.boe.es>buscar>act

${ }^{20}$ Ley Orgánica 2/2009, de 11 de diciembre, de reforma de la Ley Orgánica 4/2000, de 11 de enero, sobre derechos y libertades de los extranjeros en España y su integración social. I. Disposiciones Generales Jefatura del Estado. Boletín Oficial del Estado (BOE) Madrid. N. Boletín 299. p.104992. BOE-A-2009-19949.BOE.es https: //www.boe.es>buscar

${ }^{21}$ Ley Orgánica 2/2009, de 11 de diciembre, de reforma de la Ley Orgánica 4/2000, de 11 de enero, sobre derechos y libertades de los extranjeros en España y su integración social. I. Disposiciones Generales Jefatura del Estado. Boletín Oficial del Estado (BOE) Madrid. N. Boletín 299. p.104992. BOE-A- BOE-A-2009-19949.BOE.es https: //www.boe.es>buscar

22 Ley Orgánica 2/2009, de 11 de diciembre, de reforma de la Ley Orgánica 4/2000, de 11 de enero, sobre derechos y libertades de los extranjeros en España y su integración social. I. Disposiciones Generales Jefatura del Estado. Boletín Oficial del Estado (BOE) Madrid. N. Boletín 299. p.104994. BOE-A-BOE-A-2009-19949.BOE.es https: //www.boe.es>buscar

${ }^{23}$ Real Decreto 463/2020 de 14 de marzo, por el que se declara el estado de alarma para la gestión de la situación de crisis sanitaria ocasionada por el Covit-19 Jefatura del Estado. Boletín Oficial del Estado (BOE) Madrid. N. Boletín 67. p.25391. BOE-A-2020-3692.BOE.es https: //www.boe.es>buscar

24 Uribe Azcarate, Enrique y Gonzáles Chávez, María de Lourdes (2007) (№27) Revista de Derecho. Editorial Universidad del Norte. Barranquilla Colombia. p.223.

25 Tribunal Supremo (Sala Tercera, de lo Contencioso- administrativo) ( Sección 5a) ( Ponente: Excmo. Trillo Alonso, Juan Carlos) (Sentencia 791/2019 de 10 de junio) Rec., 5805/2017. La ley.

${ }^{26}$ Real Decreto 463/2020 de 14 de marzo, por el que se declara el estado de alarma para la gestión de la situación de crisis sanitaria ocasionada por el Covit-19 Jefatura del Estado. Boletín Oficial del Estado (BOE) Madrid. N. Boletín 67. p.25391. BOE-A-2020-3692.BOE.es https: //www.boe.es>buscar

${ }^{27}$ Ley 33/2011, de 4 de octubre, General de Salud Pública. Jefatura del Estado. Boletín Oficial del Estado (BOE) Madrid. N. Boletín 240. p.104619. BOE-A-2011-15623.BOE.es https: //www.boe.es>buscar

${ }^{28}$ Ley 33/2011, de 4 de octubre, General de Salud Pública. Jefatura del Estado. Boletín Oficial del Estado (BOE) Madrid. N. Boletín 240. p.104600. BOE-A-2011-15623BOE.es https: //www.boe.es>buscar

${ }^{29}$ Ley 17/2015, de 9 de julio, del Sistema Nacional de Protección Civil. Jefatura del Estado. Boletín Oficial del Estado (BOE) Madrid. N. Boletín 164. p.27. BOE-A-2015-7730.BOE.es https: //www.boe.es>buscar

${ }^{30}$ Ley 17/2015, de 9 de julio, del Sistema Nacional de Protección Civil. Jefatura del Estado. Boletín Oficial del Estado (BOE) Madrid. N. Boletín 164. p.27. BOE-A-2015-7730.BOE.es https: //www.boe.es>buscar

31 Código Penal (2006). Consejo General de la Abogacía Española. Editorial. La Ley (Madrid). p.196.

${ }_{32}^{32}$ Código Penal (2006). Op. Cit., p.196.

33 Periódico Croníca.p.1. https://cronicaglobal.elespanol..com>vida>denunciado-toseradrede-cara-... 
${ }^{34}$ Orden INT/227/2020, de 15 de marzo, en relación con las medidas que se adoptan en el ámbito de Instituciones Penitenciarias al amparo del Real Decreto 463/2020, de 14 de marzo, por el que se declara el estado de alarma para la gestión de la situación de crisis sanitaria ocasionada por el COVID-19. I. Disposiciones Generales. Ministerio del Interior. Boletín Oficial del Estado (BOE) Madrid. N. Boletín 68. p.1.BOE.es https: //www.boe.es>buscar>pdf> BOE-A-2020-3695>consolidado

${ }^{35}$ Orden INT/227/2020, de 15 de marzo, en relación con las medidas que se adoptan en el ámbito de Instituciones Penitenciarias al amparo del Real Decreto 463/2020, de 14 de marzo, por el que se declara el estado de alarma para la gestión de la situación de crisis sanitaria ocasionada por el COVID-19. I. Disposiciones Generales. Ministerio del Interior. Boletín Oficial del Estado (BOE) Madrid. N. Boletín 68. p.1.BOE.es https: //www.boe.es>buscar>pdf> BOE-A-2020-3695>consolidado

${ }^{36}$ Real Decreto 463/2020 de 14 de marzo, por el que se declara el estado de alarma para la gestión de la situación de crisis sanitaria ocasionada por el Covit-19 Jefatura del Estado. Boletín Oficial del Estado (BOE) Madrid. N. Boletín 67. p.25392. BOE-A-2020-3692.BOE.es https: //www.boe.es>buscar

${ }^{37}$ Real Decreto 463/2020 de 14 de marzo, por el que se declara el estado de alarma para la gestión de la situación de crisis sanitaria ocasionada por el Covit-19 Jefatura del Estado. Boletín Oficial del Estado (BOE) Madrid. N. Boletín 67. p.25392. BOE-A-2020-3692.BOE.es https: //www.boe.es>buscar

${ }^{38}$ Real Decreto 463/2020 de 14 de marzo, por el que se declara el estado de alarma para la gestión de la situación de crisis sanitaria ocasionada por el Covit-19 Ministerio de la Presidencia, Relaciones con las Cortes y Memoria Democrática. Boletín Oficial del Estado (BOE) Madrid. N. Boletín 73. p.1. BOE-A-2020-3828.BOE.es https: //www.boe.es>buscar (modificado 2020/03/18) por lo que los menores podrán salir a la calle siempre acompañados y, las demás personas deberán ir solas por la calle y no acompañadas.

${ }^{39}$ Ley Orgánica 4/1981, de 1 de junio, de los estados de alarma, excepción y sitio. Jefatura del Estado. Boletín Oficial del Estado (BOE) Madrid. N. Boletín 134. BOE-A-1981-12774. p.5. https: //www.boe.es>buscar

${ }^{40}$ Real Decreto 463/2020 de 14 de marzo, por el que se declara el estado de alarma para la gestión de la situación de crisis sanitaria ocasionada por el Covit-19 Jefatura del Estado. Boletín Oficial del Estado (BOE) Madrid. N. Boletín 67. p.25353. BOE-A-2020-3692.BOE.es https: //www.boe.es>buscar

${ }^{41}$ Real Decreto 463/2020 de 14 de marzo, por el que se declara el estado de alarma para la gestión de la situación de crisis sanitaria ocasionada por el Covit-19 Jefatura del Estado. Boletín Oficial del Estado (BOE) Madrid. N. Boletín 67. p.25396. BOE-A-2020-3692.BOE.es https: //www.boe.es>buscar

42 Instrucción de 15 de marzo de 2020, del Ministerio de Defensa, por la que se establecen medidas para la gestión de la situación de crisis sanitaria ocasionada por el COVID-19 en el ámbito del Ministerio de Defensa. I. Disposiciones Generales. Ministerio de Defensa Boletín Oficial del Estado (BOE) Madrid. N. Boletín 68. p.25401. BOE-A-2020-343.BOE.es https: //www.boe.es>calendario $>15 / 03 / 20$

43 Instrucción de 15 de marzo de 2020, del Ministerio de Defensa, por la que se establecen medidas para la gestión de la situación de crisis sanitaria ocasionada por el COVID-19 en el ámbito del Ministerio de Defensa. I. Disposiciones Generales. Ministerio de Defensa Boletín Oficial del Estado (BOE) Madrid. N. Boletín 68. p.25402. BOE-A-2020-3693.BOE.es https: //www.boe.es>calendario>15/03/20

${ }^{44}$ EM Madrid p.1 https://www.elmundo.es>Inicio>España 
${ }^{45}$ Real Decreto 463/2020 de 14 de marzo, por el que se declara el estado de alarma para la gestión de la situación de crisis sanitaria ocasionada por el Covit-19 Jefatura del Estado. Boletín Oficial del Estado (BOE) Madrid. N. Boletín 67. p.25396. BOE-A-2020-3692.BOE.es https: //www.boe.es>buscar

${ }^{46}$ Real Decreto 463/2020 de 14 de marzo, por el que se declara el estado de alarma para la gestión de la situación de crisis sanitaria ocasionada por el Covit-19 Jefatura del Estado. Boletín Oficial del Estado (BOE) Madrid. N. Boletín 67. pps.25394-25395. BOE-A-20203692.BOE.es https: //www.boe.es>buscar

${ }^{47}$ Orden TMA/229/2020, de 15 de marzo, por la que dictan disposiciones respecto al acceso de los transportistas profesionales a determinados servicios necesarios para facilitar el transporte de mercancías en el territorio nacional I Disposiciones Generales. Ministerio de Transportes, Movilidad y Agenda Urbana. Boletín Oficial del Estado (BOE) Madrid. N. Boletín 68. p.25417. BOE-A-2020-3693 BOE.es https: //www.boe.es>calendario>15/03/20

${ }^{48}$ Real Decreto 463/2020 de 14 de marzo, por el que se declara el estado de alarma para la gestión de la situación de crisis sanitaria ocasionada por el Covit-19 Jefatura del Estado. Boletín Oficial del Estado (BOE) Madrid. N. Boletín 67. p.25396. BOE-A-2020-3692.BOE.es https: //www.boe.es>buscar

49 Orden Int/ 248/2020, de 16 de marzo, por la que se establecen criterios de actuación para las Fuerzas y Cuerpos de Seguridad ante el restablecimiento temporal de controles fronterizos. I. Disposiciones Generales. Ministerio del Interior. Boletín Oficial del Estado (BOE) Madrid. N. Boletín 73. p.25900. BOE-A-2020-3825.BOE.es https: //www.boe.es>días>2020>03>18>pdfs> BOE-A-2020-3825

${ }^{50}$ Orden PCM/205/2020, de 10 de marzo, por la que se publica el Acuerdo del Consejo de Ministros de 10 de marzo de 2020, por el que se establecen medidas excepcionales para limitar la propagación y el contagio por el COVID-19. I Disposiciones Generales, Ministerio de la Presidencia, Relaciones con las Cortes y Memoria Democrática. Boletín Oficial del Estado (BOE) Madrid. N. Boletín 61. p.24168. BOE-A-2020-3433.BOE.es https: //www.boe.es $>$ calendario $>10 / 03 / 20$

${ }^{51}$ Orden PCM/216/2020, de 12 de marzo, por la que se publica el Acuerdo del Consejo de Ministros de 12 de marzo de 2020, por el que se establecen medidas excepcionales para limitar la propagación y el contagio por el COVID-19, mediante la prohibición de entrada de buques de pasaje procedentes de la República italiana y de cruceros de cualquier origen con destino a puertos españoles. I Disposiciones Generales, Ministerio de la Presidencia, Relaciones con las Cortes y Memoria Democrática. Boletín Oficial del Estado (BOE) Madrid. N. Boletín 64. p.24994. BOE-A-2020-3579.BOE.es https: //www.boe.es>calendario $>12 / 03 / 20$

52 Orden PCM/216/2020, de 12 de marzo, por la que se publica el Acuerdo del Consejo de Ministros de 12 de marzo de 2020, por el que se establecen medidas excepcionales para limitar la propagación y el contagio por el COVID-19, mediante la prohibición de entrada de buques de pasaje procedentes de la República italiana y de cruceros de cualquier origen con destino a puertos españoles. I Disposiciones Generales, Ministerio de la Presidencia, Relaciones con las Cortes y Memoria Democrática. Boletín Oficial del Estado (BOE) Madrid. N. Boletín 64. p.24995. BOE-A-2020-3579.BOE.es https: //www.boe.es>calendario $>12 / 03 / 20$

${ }^{53}$ Real Decreto 463/2020 de 14 de marzo, por el que se declara el estado de alarma para la gestión de la situación de crisis sanitaria ocasionada por el Covit-19 Jefatura del Estado. Boletín Oficial del Estado (BOE) Madrid. N. Boletín 67. p.25390. BOE-A-2020-3692.BOE.es https: //www.boe.es>buscar 
${ }^{54}$ Ley Orgánica 2/2006, de 3 de mayo, de Educación. Jefatura del Estado. Boletín Oficial del Estado (BOE) Madrid. N. Boletín 67. p 17. BOE-A-2006-7899.BOE.es https: //www.boe.es>buscar>act 